\title{
DESAFIOS PARA A REGULAÇÃO: TRABALHO AUTÔNOMO E O DIREITO DO TRABALHO
}

\section{CHALLENGES FOR REGULATION: AUTONOMOUS WORK AND LABOR LAW}

Ana Virgínia Moreira Gomes ${ }^{*}$

Patrícia Tuma Martins Bertolin

\section{RESUMO}

O objetivo deste estudo é o de analisar os desafios regulatórios trazidos pelo trabalho autônomo, cujas condições de trabalho estão fora do raio de abrangência do direito do trabalho. Para isso, inicialmente, desenvolvemos uma breve análise conceitual; a seguir, examinamos as questões jurídicas mais correntes no ordenamento brasileiro e a experiência espanhola; terceiro, analisamos o surgimento e desenvolvimento de um novo tipo de profissional diferenciado - o ipro. Por fim, considerando quais as possibilidades regulatórias para as relações de trabalho autônomo. A metodologia da pesquisa é bibliográfica e documental.

Palavras-chave: Trabalho autônomo; Profissional Liberal; Ipros

\begin{abstract}
The aim of this study is to analyze the regulatory challenges posed by self-employment work, whose labour conditions are outside the scope of labor law. For this purpose, initially we developed a brief conceptual analysis; then, we examine the most common legal issues in the Brazilian legal system and the Spanish experience; third, we analyze the emergence and development of a new type of self-employed worker - the ipro. Finally, we consider the regulatory possibilities for the relations of self-employment work. The research methodology is bibliographical and documentary. El enigma del trabajo no cesa de resurgir bajo formas nuevas, y de minar la validez de las respuestas imaginadas para resolverlo
\end{abstract}

\footnotetext{
- Doutora em Direito do Trabalho pela Faculdade de Direito pela Universidade de São Paulo - USP, São Paulo, (Brasil). Professora do Curso de Graduação em Direito e do Programa de Pós-Graduação em Direito Constitucional da Universidade de Fortaleza- UNIFOR.

E-mail: avmgomes@gmail.com

- Doutora em Direito do Trabalho pela Faculdade de Direito pela Universidade de São Paulo, USP, São Paulo, (Brasil). Professora do Programa de Pós-Graduação em Direito Político e Econômico da Universidade Presbiteriana Mackenzie - UPM.
} 
Keywords: Self-employed worker; Liberal Professional; Ipros.

\section{INTRODUÇÃO}

Desde o advento da globalização econômica, o trabalho vem apresentando formas distintas da tradicional relação de emprego subordinada e não eventual entre um empregador e um empregado. Por razões de naturezas diversas - econômica, administrativa, de índole pessoal empresas e trabalhadores contratam a prestação de serviço criando relações que se diferenciam da relação de emprego em algum aspecto. A terceirização é um importante exemplo nesse tema, tanto que a Organização Internacional do Trabalho em 2006 aprovou a Recomendação n.198 que trata das condições para se determinar a existência de uma relação de emprego e de sua proteção diante da multiplicidade de diferentes formas de se trabalhar, inclusive em relações triangulares de trabalho.

Um aspecto essencial nessa questão trata de trabalhadores que, em razão de características, próprias da sua atividade, são mais propensos a prestar seu trabalho de um modo distinto daquela prestada pelo empregado típico. O exemplo mais característico desse tipo de trabalhador é o profissional liberal - no direito, medicina arquitetura, por exemplo.

$\mathrm{O}$ direito do trabalho, no entanto, alheio a essa complexidade, se funda em duas dicotomias: a primeira, entre empregado e empregador; e a segunda, entre trabalhador autônomo e trabalhador subordinado. Assim, fundada no critério da subordinação jurídica, a lei determina que o trabalhador ou é um empregado, ou um autônomo. Se empregado, atrai para si todas as proteções garantidas por lei, inclusive no que diz respeito à sindicalização e negociação coletiva. Se autônomo, suas condições de trabalho estão fora do raio de abrangência do direito do trabalho.

Essa visão dualista e excludente não abarca a complexidade do mercado de trabalho atual. Neste artigo, nosso objetivo é o de analisar os desafios regulatórios vindos a partir da emergência de diferentes tipos de trabalho autônomo. Para isso, inicialmente, desenvolvemos uma breve análise conceitual; a seguir, examinamos as questões jurídicas mais correntes no ordenamento brasileiro; terceiro, analisamos o exemplo da Espanha que adotou uma lei do trabalho autônomo; a seguir, analisamos o surgimento e desenvolvimento de um novo tipo de profissional diferenciado - o ipro. Por fim, concluímos considerando as possibilidades regulatórias as suas relações de trabalho autônomo. 
A metodologia é desenvolvida através de análise bibliográfica e documental, constituindo a pesquisa em um estudo qualitativo com finalidade descritiva, explicativa e exploratória.

\section{Limitações teóricas do direito do trabalho na proteção às relações de trabalho autônomas}

O direito do trabalho foi concebido e sistematizado para regular e proteger o trabalho subordinado em uma relação de emprego. Uma vez que o trabalho da maioria dos trabalhadores se enquadrava na descrição de tais relações, transformar a relação de emprego na relação padrão que atrai toda a proteção garantida pelo direito do trabalho parecia a melhor maneira de assegurar a justiça social. Os trabalhadores independentes foram excluídos da proteção do direito do trabalho e sua relação de trabalho autônoma vista, na maioria das vezes, de modo suspeito pelo receio de fraudes que buscassem evitar os custos trabalhistas.

A opção feita de se focar na relação de emprego foi relativamente bem-sucedida ao longo do século XX, até que a globalização tornou o mundo do trabalho muito mais complexo. Por um lado, os trabalhadores empregados experimentam formas extremas de precariedade nas condições de trabalho (tais quais, os contratos de "zero hora", terceirização, contratos temporários); por outro, é cada vez mais evidente que os trabalhadores em relações autônomas ou mesmo em relações que não se definem completamente pelo modelo de uma relação de emprego típica - por exemplo, os trabalhadores domésticos - estão muitas vezes em situações de extrema vulnerabilidade e necessitam da proteção legal. ${ }^{1}$

A fim de continuar a ser eficaz em garantir a justiça social, o direito do trabalho deve reconsiderar a sua opção de constituir a relação de emprego como ponto de atração principal da proteção por esse conferida e pensar diferentes modelos de regulação que podem de uma forma eficaz proteger os trabalhadores do outro lado da cerca de trabalho subordinado.

O direito do trabalho, no entanto, parece enfrentar dificuldades em estabelecer limites e em especial no que concerne ao trabalho realizado fora do paradigma de uma relação de emprego. O direito brasileiro segue o modelo de dicotomia fundada na subordinação jurídica e divide os trabalhadores em empregados e autônomos para fins de inclusão do trabalhador no

\footnotetext{
${ }^{1}$ Sobre a regulação do trabalho doméstico, ver GOMES \& TORTELL, 2015.
} 
campo de abrangência da proteção do direito do trabalho. O trabalho autônomo ${ }^{2}$ usualmente está associado ao trabalho informal em razão da falta de políticas para sua inserção no mercado de trabalho. As consequências dessa inadequação se refletem no desconhecimento acerca das condições de trabalho desses profissionais, de suas necessidades no que concerne ao desenvolvimento de políticas públicas específicas, de sua forma de representação, etc.

\section{Questões conceituais referentes ao direito brasileiro.}

O direito brasileiro segue o modelo de dicotomia fundada na subordinação jurídica e divide os trabalhadores em empregados e autônomos para fins de inclusão do trabalhador no campo de abrangência do direito do trabalho. Dentro dessa dicotomia, no entanto, o direito reconhece algumas profissões que em razão de características advindas de sua própria atividade possuem uma regulação específica. Conforme esse raciocínio, a lei se utiliza dos seguintes conceitos: categoria profissional diferenciada, profissionais liberais, profissões reguladas e trabalhadores intelectuais.

Iniciando pelos últimos, a CLT estabelece que, no que concerne ao empregado, não há que se diferenciar entre "o trabalho intelectual, técnico e manual" (Art. 3º, CLT). Conforme Alice Monteiro de Barros (2004, p. 148), trabalhadores intelectuais são aqueles "cujo trabalho pressupõe uma cultura científica ou artística, como o advogado, o médico, o dentista, o engenheiro, o artista, entre outros". Ainda assim, a própria CLT estabelece distinções em relação a certas profissões que se consideram "diferenciadas por força de estatuto profissional especial ou em consequência de condições de vida singulares" (Art. 511, §3º, CLT). Esses trabalhadores no sistema sindical corporativista formam as categorias profissionais diferenciadas.

A CLT não se refere expressamente aos profissionais liberais. Conforme Leighton (2014, p. 29), esses profissionais podem ser definidos por aqueles que exercem atividades para as quais são necessários longos períodos de treinamento ou educação, reguladas por regras profissionais estritas e com um senso forte de ética profissional. Porém, pode-se interpretar que o sentido do Art. 511, $\S 3^{\circ}$, da CLT abrange os profissionais liberais. Para sanar, todavia, qualquer dúvida interpretativa acerca do alcance do Art. 511, foi aprovado em junho de 2014, pela Comissão de

\footnotetext{
2 Terminologia: trabalho autônomo e trabalho por conta própria, "atividades não assalariadas que geram renda" (MESQUITA, p. 12).
} 
Constituição e Justiça e de Cidadania da Câmara dos Deputados o projeto de lei 6320/09 que inclui profissionais liberais como uma espécie de categoria profissional diferenciada. No momento da conclusão desse estudo, o projeto seguia para o Senado.

Não há nenhuma correlação entre trabalhadores com profissão regulada e profissionais liberais, uma vez que muitos trabalhadores com profissões reguladas não se enquadram no conceito de profissional liberal - como, por exemplo, o secretário, arquivista, auxiliar em saúde bocal. Ademais, no caso dos trabalhadores com profissão regulada, a regulação pode tratar de dimensões bem específicas da atividade profissional. No que concerne à relação entre as profissões reguladas e as categorias diferenciadas, considerando-se que o quadro de categorias a que se refere o Art. 577 da CLT encontra-se bastante desatualizado, muitas atividades reguladas passaram a ser consideradas categorias profissionais diferenciadas pela via judiciária. É o caso dos vigilantes, cujo trabalho está regulado pelas Leis 7.102/83 e 8.863/94. No caso, conforme o TST:

As condições de vida singulares dos vigilantes, assim como a regulamentação da atividade por estatuto profissional especial, faz com que seja definida como categoria diferenciada, nos termos do artigo 511, $\S 3^{\circ}$, da CLT. TST, Ac. $6^{\text {a }}$ Turma, RECURSO DE REVISTA : RR 378009320075040741

Em síntese, o direito do trabalho admite certas especificidades na regulação justificada pelas características peculiares da atividade exercida que se reflita em uma regulação especial daquela profissão. Tal ideia se concretiza no conceito de categorias profissionais diferenciadas, que inclui as profissões liberais. Essa distinção feita pela lei, no entanto, encontra-se ainda dentro das dicotomias: empregador-empregador e empregado-trabalhador autônomo.

\section{Questões Jurídicas referentes ao direito brasileiro}

Diante do quadro conceitual exposto no item anterior, algumas questões jurídicas são mais recorrentes no Brasil. Primeiro, no que concerne ao enquadramento sindical do trabalhador integrante de categoria profissional diferenciada. Esses trabalhadores se organizam em sindicatos por profissão, independente da atividade econômica preponderante da empresa. Assim, serão representados e se beneficiarão da negociação coletiva negociada pelo sindicado específico da categoria profissional diferenciada. 
Observações essenciais quanto a essa matéria tratam, inicialmente, da estabilidade no emprego se o trabalhador for eleito dirigente sindical. Conforme o Enunciado 369 do TST: "II - O empregado de categoria diferenciada eleito dirigente sindical só goza de estabilidade se exercer na empresa atividade pertinente à categoria profissional do sindicato para o qual foi eleito dirigente". Portanto, a função do trabalhador na empresa é que determina o seu enquadramento sindical e, consequentemente, o pagamento da contribuição sindical. Se o trabalhador for representado pelo sindicado da categoria profissional diferenciada, é para esse sindicato que deve ser repassada a contribuição. ${ }^{3}$ Segundo, no que concerne à negociação coletiva, conforme o Enunciado 374 TST: "Empregado integrante de categoria profissional diferenciada não tem o direito de haver de seu empregador vantagens previstas em instrumento coletivo no qual a empresa não foi representada por órgão de classe de sua categoria. (ex-OJ n ${ }^{\circ}$ 55 da SBDI-1 - inserida em 25.11.1996)".

A pertença a uma categoria profissional diferenciada (e o exercício dessa profissão na empresa) também gera consequências para os direitos decorrentes de lei. Assim, conforme o Enunciado $\mathrm{n}^{\mathrm{o}} 117$ do TST: "Não se beneficiam do regime legal relativo aos bancários os empregados de estabelecimentos de crédito pertencentes a categorias profissionais diferenciadas".

Por fim, uma questão essencial no que diz respeito a esses profissionais diferenciados trata da sua posição frente às duas dicotomias sob as quais se funda o direito do trabalho: empregado-empregador e empregado-trabalhador autônomo. Essa questão não é alcançada, nem é mesmo o foco, do conceito de categoria profissional diferenciada. Porém, é relevante para certos trabalhadores que por condições singulares de sua atividade podem facilmente se situar em quaisquer dos lados dessas dicotomias. Via de regra, profissionais liberais podem oferecer seu conhecimento especializado de formas distintas.

Assim, o advogado pode exercer seu trabalho de forma autônoma ou como empregado de um escritório de advocacia, sob subordinação jurídica. A diferença nesses casos é sutil, exigindo-se a realização de testes para averiguar a existência da subordinação jurídica. Por exemplo, no caso do advogado-empregado, trabalhar apenas para um escritório, nas suas dependências, usando equipamentos do escritório, obedecendo a horários e tarefas determinadas pelo escritório e se reportando a superiores hierárquicos. Por outro lado, em

\footnotetext{
${ }^{3}$ Ressalta-se que o repasse da contribuição sindical não está condicionado à efetiva negociação de acordo ou convenção pelo sindicato da categoria diferenciada, já que o próprio Art. 592 da CLT não arrola a negociação coletiva como uma das atividades a serem custeadas pela contribuição sindical.
} 
decisão do TST, o tribunal negou vínculo empregatício à advogada que "possuía cotas na empresa, recebia pró-labore e distribuição de lucros correspondentes a suas cotas" (Recurso de Revista $\mathrm{n}^{\circ}$ TST-AIRR-1822-09.2010.5.02.0029). Os tribunais buscam indícios de uma relação de emprego na atuação do profissional a partir da presença dos pressupostos de uma relação de emprego: trabalho exercido por pessoa física, subordinação jurídica, pessoalidade, nãoeventualidade, onerosidade.

Há, no entanto, vasto debate na literatura acerca de quão adequados são tais testes diante de formas complexas de trabalho que são simplesmente taxadas de trabalho autônomo e ignoradas pelo direito. As consequências dessa inadequação se refletem no desconhecimento acerca das condições de trabalho desses profissionais, de suas necessidades no que concerne ao desenvolvimento de políticas públicas específicas, de sua forma de representação, etc.

Leighton e Wynn (2011, p.2), por exemplo, defendem que o direito do trabalho se distancie da posição que vê o trabalho autônomo "como pouco mais do que um '"default' da categoria do empregado. A integridade e o valor de todas as relações de trabalho devem ser reconhecidos, cada um com suas próprias características". 4

No mesmo sentido, Freedland (2006, p.4) defende a transição do contrato de trabalho para a noção mais ampla de contrato de trabalho pessoal que abrangeria todas as relações que têm como objetivo a prestação de um trabalho de modo pessoal. Como o autor adverte, "Esta é uma mudança a partir da análise unificada do contrato de trabalho para o reconhecimento de um grupo de contratos de trabalho pessoal diversos, ainda que interligados"5 (Freedland, 2006, p.4).

O argumento do autor é de que no outro lado da cerca do emprego, onde se situam o trabalho quase-subordinado e autônomo, há um buraco negro no que se refere a um sistema de princípios e regras que regessem essas atividades (FREEDLAND, 2006, p.6). Por fim, Freedland resume bem a perspectiva do direito do trabalho (e de seus operadores) acerca de contratos de relação de trabalho que estão do "outro lado da cerca" do trabalho subordinado:

Nesse vasto campo de contratos de trabalho pessoal, encontramos uma enorme variedade de padrões reais de acordos de trabalho ... Como advogados trabalhistas, parece que abordamos esse mundo diverso de uma perspectiva inteiramente externa, a partir do contrato de trabalho. Ou seja,

\footnotetext{
${ }^{4}$ Tradução livre: "as little more than a 'default' category of employee status. The integrity and worth of all work relationships should be recognised, each with its own characteristics".

5 Tradução livre: "This is a shift from unified analysis of the contract of employment to the recognition of a diverse though inter-linked family of personal work contracts"
} 
analisamos contratos de trabalho autônomos, considerando se esses constituem contratos de trabalho subordinado. Se não o forem, nós consideramos se eles podem ser considerados contratos de trabalho subordinado por analogia. Se eles não puderem, tendemos a concluir que eles estão fora da nossa área, algum tipo de contrato de negócios com os quais não estamos realmente preocupados. Estamos preparados para reconhecer a diversidade dentro do contrato de trabalho subordinado, e estamos nos tornando mais acostumados do que estávamos a reconhecer a diversidade nas margens do contrato de trabalho subordinado; mas acho que ainda nos permitimos estar bastante condicionados pelo paradigma do contrato de trabalho subordinado (Freedland, 2006, p.6). ${ }^{6}$

A seguir, o analisamos a iniciativa espanhola de regular o trabalho autônomo.

\section{Regulação do trabalho autônomo? O exemplo da Espanha.}

$\mathrm{Na}$ última década, alguns países europeus aprovaram estatutos dos trabalhadores autônomos: a Ley 20/2007, de 11 de Julio (Ley del Estatuto del Trabajo Autónomo- LETA) na Espanha, e a Holanda, em 2013, o Social Akkord. Tomando o exemplo espanhol como caso de estudo, passamos a analisar as disposições da LETA. De acordo com Pérez Rey (2016), a LETA inova ao trazer a figura do trabalho autônomo dependente (trabajador autónomo dependiente - TRADE) e sistematiza a regulação do trabalho autônomo. O autor explica que a estratégia de regular esse tipo de trabalho parece constituir "una forma limitada de reversión de los procesos de expulsión de la norma laboral que se habían producido en la reforma de 1994 respeto de categorías precisas como la de transportistas o agentes comerciales" 7, que podem ser caracterizados como trabalhadores autônomos dependentes.

A LETA assegura o $\mathrm{O}$ Artigo $1^{\circ}$ da LETA define o trabalhador autônomo como:

a las personas físicas que realicen de forma habitual, personal, directa, por cuenta propia y fuera del ámbito de dirección y organización de otra persona, una actividad económica o profesional a título lucrativo, den o no ocupación a trabajadores por cuenta ajena. Esta actividad autónoma o por cuenta propia podrá realizarse a tiempo completo o a tiempo parcial.

Quanto aos trabalhadores autônomos dependentes, o Artigo 11 da LETA dispõe que:

\footnotetext{
${ }^{6}$ Tradução livre: In this extended realm of personal work contracts, we find an enormous variety of factual patterns of work arrangements...As employment lawyers, we seem to approach this diverse world entirely from the contract of employment outwards. That is to say, we analyse such arrangements by considering whether they constitute contracts of employment. If they do not, we consider whether they can be analogised to contracts of employment. If they cannot, we tend to conclude that they are outside our province, some kind of business contract with which we are not really concerned. We are prepared to recognise diversity within the contract of employment, and we are becoming more accustomed than we were to recognising diversity on the margins of the contract of employment; but I think we are still allowing ourselves to be rather tightly constrained by the contract of employment paradigm.

${ }^{7}$ Sobre as reformas flexibilizadoras de 1994, cf. SAPPIA, 1996.
} 
son aquéllos que realizan una actividad económica o profesional a título lucrativo y de forma habitual, personal, directa y predominante para una persona física o jurídica, denominada cliente, del que dependen económicamente por percibir de él, al menos, el 75 por ciento de sus ingresos por rendimientos de trabajo y de actividades económicas o profesionales.

A LETA assegura aos trabalhadores autônomos os direitos fundamentais e liberdades públicas garantidos na Constituição espanhola e nos tratados internacionais de direitos humanos ratificados pela Espanha (Artigo $4^{\circ}$, LETA). O Estatuto ressalta o direito à liberdade profissional, à livre concorrência, de propriedade intelectual, à intimidade, à proteção de sua saúde e segurança, à proteção contra assédio sexual. Outrossim, o trabalhador autônomo tem o direito de não ser discriminado por "razón de nacimiento, origen racial o étnico, sexo, estado civil, religión, convicciones, discapacidad, edad, orientación sexual, ...o circunstancia personal o social" (LETA, Artigo 4.3). A LETA se refere ainda ao direito de igualdade das pessoas com deficiência, de acordo com a Ley General de derechos de las personas con discapacidad y de su inclusión social, aprovada pelo Real Decreto Legislativo 1/2013.

Quanto aos trabalhadores autônomos dependentes, a LETA cria um tipo de contrato coletivo denominado "acuerdo de interés profesional" (Artigo 13) a ser negociado entre as associações desses trabalhadores e as empresas que atuam na área de interesse e deve dispor sobre as condições de trabalho. Dentre as condições mínimas de trabalho, ressalta-se férias anuais, limitação de jornada, equilíbrio entre responsabilidades familiares e trabalho, normas a proteção contra o fim do contrato sem justa causa. No que concerne à última disposição, se a relação contratual se extinguir sem justa causa, o trabalhador autônomo dependente terá direito à indenização.

Conforme o Artigo 15.1 da LETA, a relação contratual poderá findar por:

a) Mutuo acuerdo de las partes.b) Causas válidamente consignadas en el contrato, salvo que las mismas constituyan abuso de derecho manifiesto. c) Muerte y jubilación o invalidez incompatibles con la actividad profesional, conforme a la correspondiente legislación de Seguridad Social. d) Desistimiento del trabajador autónomo económicamente dependiente, debiendo en tal caso mediar el preaviso estipulado o conforme a los usos y costumbres. e) Voluntad del trabajador autónomo económicamente dependiente, fundada en un incumplimiento contractual grave de la contraparte.f) Voluntad del cliente por causa justificada, debiendo mediar el preaviso estipulado o conforme a los usos y costumbres.g) Por decisión de la trabajadora autónoma económicamente dependiente que se vea obligada a 
extinguir la relación contractual como consecuencia de ser víctima de

violencia de género.h) Cualquier otra causa legalmente establecida.

Ressalta-se, ainda, no que concerne a todos os trabalhadores autônomos o direito à liberdade sindical. Conforme o Artigo 19 da LETA, os trabalhadores autônomos possuem o direito de:

a) Afiliarse al sindicato o asociación empresarial de su elección, en los términos establecidos en la legislación correspondiente. b) Afiliarse y fundar asociaciones profesionales específicas de trabajadores autónomos sin autorización previa. c) Ejercer la actividad colectiva de defensa de sus intereses profesionales.

Sem entrar no debate sobre os efeitos da LETA no atual cenário de crise do direito do trabalho espanhol - já que o objetivo deste estudo se restringe ao questionamento acerca da possibilidade de se regular o trabalho do autônomo dada a sua importância no mercado de trabalho - podemos sugeria que a LETA constitui um marco regulatório para outros países acerca desse desafio.

Na próxima seção, examinamos um exemplo importante do novo tipo profissional que desafia a tradicional regulação do direito do trabalho: os ipros.

\section{Um novo olhar sobre o profissional diferenciado: o Ipro}

De 2004 a 2013, independente professionals ou ipros cresceram de 6.2 milhões para 9 milhões - um crescimento de 45\% - nos países da União Européia 27, apesar da crise financeira de 2008 (LEIGHTON; BROWN, 2014, p.16). ${ }^{8}$ Os ipros são o grupo profissional que mais cresce na União Européia, constituindo 5\% do seu mercado de trabalho (LEIGHTON, 2014, p.84). O aumento se deu, em especial, em países que não tiveram seu crescimento econômico tão afetado pela crise - o que indica que o ipro não constitui uma válvula de escape do mercado de trabalho diante da escassez de bons empregos ou uma forma disfarçada de precarização da relação de emprego. Mas o que são os ipros?

Os ipros são profissionais independentes. Não são empregados, nem empregadores ou empreendedores, uma vez que não almejam iniciar e construir uma empresa ou empregarem outros trabalhadores. São profissionais qualificados que oferecem sua expertise de forma independente. São "trabalhadores autônomos, sem empregados, que atuam em uma atividade intelectual ou técnica, fora dos setores de agropecuária e comércio" (RAPELLI, 2012, p. 4),

\footnotetext{
${ }^{8}$ Em alguns países o crescimento foi ainda maior: $93 \%$ na Holanda, $85 \%$ na França, $63 \%$ no Reino Unido, $56 \%$ na Finlândia, apesar de apenas $12 \%$ na Itália (LEIGHTON, 2014, p.88).
} 
como por exemplo, design, música, marketing, jornalismo, tecnologia, medicina e atividades na área da saúde. É uma tendência crescente entre os profissionais liberais - 30\% dos i-pros estão engajados em uma atividade profissional, científica ou técnica e 14\% nas áreas da saúde e serviço social (RAPELLI, 2012, p.4).

Cabe questionar se os ipros não seriam simplesmente trabalhadores autônomos.

Respondendo a essa questão ressalta-se que esses profissionais se situam dentro do grupo dos trabalhadores autônomos, mas se destacam por serem profissionais que atuam em atividades que requerem conhecimento intelectual ou técnico (LEIGHTON, 2014, p.25). Outra forma de se destacar os ipros dentre os trabalhadores autônomos é a que se refere às motivações para se tornar um ipro. Em entrevista com um grupo representativo desses profissionais de vários países da União Européia, Leighton, conclui que

\section{Nenhum relatou qualquer sentimento de ter sido obrigado a tornar-se independente e todos trataram da independência como algo significativo, ao invés de ser parte de uma relação de trabalho convencional disfarçada para outras conveniências (fiscal ou regulamentar, por exemplo) (LEIGHTON, 2014, p.24). ${ }^{9}$}

Os principais motivos indicados por esses profissionais na sua escolha se referem à rejeição ao status de empregado (monotonia e desvalorização); priorizar o seu conhecimento/expertise; desejo de autonomia; um caminho natural da profissão (por exemplo, no caso de advogados); incentivos financeiros. Os ipros, portanto, escolhem não ter uma relação de emprego e não estão em uma relação de emprego disfarçada com a motivação de diminuir os custos de seu trabalho pelo não cumprimento de normas trabalhistas, previdenciárias e tributárias.

Apesar da rápida expansão dessa forma de trabalho, o ambiente regulatório (por exemplo, de seguridade social, trabalhista, de regulação profissional e de apoio e promoção) para os ipros ainda não se dá de modo sistemático. Na União Europeia, o conceito de ipro se situa em uma área cinza (status híbrido) entre o empregado e o empregador, de modo que esses profissionais não são reconhecidos por políticas públicas e legislações específicas. As políticas públicas voltadas para as empresas são inadequadas para esses profissionais. Por exemplo, políticas empresariais tratam de criação de empregos e inovações tecnológicas, porém o ipro não tem a finalidade de se tornar uma empresa ou de empregar outros trabalhadores

\footnotetext{
${ }^{9}$ Tradução livre: None reported any sense of having been compelled to become independent and all reported independence as meaningful, rather than being a conventional employment relationship disguised for other conveniences (tax or regulatory, for example).
} 
(LEIGHTON, 2014, p.28). Outro exemplo, são as normas previdenciárias: "há custos adicionais para trabalhadores autônomos acessarem o sistema de benefícios da seguridade social em sete dos nove Estados membros examinados" (LEIGHTON, 2014, p.31). ${ }^{10}$ No mesmo sentido, há limitações relativas aos benefícios de seguridade social, por exemplo, seguro-desemprego, seguro saúde e por acidentes de trabalho. ${ }^{11}$ Se por um lado os ipros são livres e autônomos para gerenciar seu trabalho, por outro, são responsáveis por si mesmo diante da lei (LEIGHTON, 2014, p.32).

\section{O ipro e a relação de emprego}

Sobre o tema, inicialmente é importante ressaltar que, como explica Romita (2006, p.15), “A prestação de serviços por um trabalhador autônomo dá ensejo a uma relação de trabalho, não a uma relação de consumo". Para o autor:

Na relação de trabalho, o prestador de serviço não vende sua energia laborativa, não almeja lucro, apenas presta serviço mediante remuneração. Depende do trabalho para viver, não para atuar como negociante no mercado. Trabalho é fator da produção, não objeto de negócio no mercado de consumo. (ROMITA, 2006, p.17)

Conclui-se assim que a relação contratual entre o trabalhador autônomo e o tomador do serviço é uma relação de trabalho. Especificamente, no que concerne aos ipros, outro aspecto controverso trata da sua diferenciação em relação aos empregados. Distintos países possuem diferentes testes de subordinação que, por vezes, não se aplicam de modo adequado aos ipros, profissionais altamente qualificados e com autonomia na execução das suas atividades.

Um exemplo interessante de como esse tipo de profissional passa a desenvolver relações que não se definem pela relação de emprego e, ao mesmo tempo, se diferenciam do trabalhador autônomo no seu sentido geral é o da Scott-Moncrieff and Associates Ltd (SCOMO). A SCOMO é uma firma inglesa de advogados, com somente dois diretores e cinqüienta advogados que atuam como autônomos. A firma emprega profissionais de tecnologia e comunicação, de administração e finanças. E seu grande sucesso se deve ao uso da tecnologia para ligar advogados, clientes e outros atores relevantes. A SCOMO não é um escritório de advogados tradicional, mas uma empresa que busca atender às necessidades de advogados que se encaixam na definição de um ipro:

Esses advogados são livres para trabalhar tantas horas quanto desejem. Eles também são livres para desenvolver sua própria base de clientes, não sobrecarregados por estritas cláusulas de não concorrência em seus

\footnotetext{
${ }^{10}$ Finlândia e Noruega são exceções. Tradução livre: "there are additional costs in seven out of the nine member states under review for self-employed persons to access the social security benefits system".

${ }^{11} \mathrm{Na}$ Itália e na Holanda, os ipros são excluídos do seguro-desemprego.
} 
contratos. Como uma dimensão da filosofia distinta, todos os afiliados têm os mesmos termos e condições, independentemente de, digamos, idade e experiência. SCOMO tem uma percentagem dos lucros, independentemente do tamanho da renda. Em termos de carreira, as oportunidades são iguais para todos. (LEIGHTON; BROWN, 2014, p.45). ${ }^{12}$

Diferente de firmas tradicionais, não há a seleção dos profissionais que integraram a firma (o profissional optar por ser associado, arcando com os custos decorrentes dessa associação) e nenhuma estrutura hierárquica rígida (incluindo mesmo os chamados profissionais "para-legais").

A SCOMO, além de possuir a estrutura tecnológica para interligar esses diversos profissionais e seus clientes, se responsabiliza pelos aspectos burocráticos (seguros, registros) próprios do exercício da profissão. Esse tipo de estrutura serve de forma precisa às necessidades dos ipros: as exigências burocráticas são atendidas pela empresa, que ainda proporciona a tecnologia necessária para algum tipo de trabalho colaborativo entre os diversos profissionais, enquanto o advogado pode focar na sua atividade, em relação a qual possui total controle e autonomia.

Ademais esse tipo de estrutura, na medida em que, a quantidade de trabalho é determinada pelo próprio profissional dá suporte necessário para se alcançar um equilíbrio entre trabalho e vida pessoal (LEIGHTON; BROWN, 2014, p.45). Poder-se-ia fazer um paralelo entre a SCOMO e uma cooperativa de trabalho, porém, no caso dessa empresa, cada profissional mantém sua autonomia na execução da sua atividade, não existindo, diferentemente das cooperativas, um ideal comum.

Mesmo admitindo-se a "proletarização dos intelectuais" (BARROS, 2004, p. 147) em relação nas quais a subordinação jurídica pode se encontrar de modo mais sutil, o tipo de relação descrito acima não constitui uma relação de emprego, tampouco uma relação de emprego disfarçada. Mesmo quando associados a uma empresa, como no caso da SCOMO, os ipros mantém total autonomia na escolha do seu trabalho no que concerne à sua intensidade, ao seu tempo, e à sua qualidade.

No caso, a relação entre o advogado e a SCOMO não guarda nenhum tipo de subordinação jurídica. Esses profissionais são genuinamente autônomos por opção, exercem

\footnotetext{
12 Tradução livre: "These lawyers are free to work as many hours as they wish. They are also free to develop their own client base, not burdened by tightly drafted restraint clauses in their contracts. As a dimension of the distinct philosophy, all affiliates have the same terms and conditions, regardless of, say, age and experience. SCOMO takes a percentage of earnings, regardless of size of income. In terms of career, the opportunities are the same for all".
} 
atividades altamente qualificadas e constituem um grupo em crescimento no mercado de trabalho. ${ }^{13}$ No entanto, ao se encontrarem do outro lado da cerca do trabalho subordinado e fora da abrangência do direito do trabalho, são ignorados pela literatura, pela lei e por políticas públicas (de promoção, treinamento e suporte).

As tradicionais dicotomias sob as quais se fundam o direito do trabalho (empregadoempregador \& trabalho autônomo-trabalho subordinado) vêm se tornando, por vezes, inadequadas para abarcar a complexidade que o mundo do trabalho apresenta. Seja no esforço para proteger trabalhadores autônomos mais vulneráveis, ${ }^{14}$ seja para promover e sistematizar o trabalho autônomo de maior qualificação profissional, as dicotomias do direito do trabalho são insuficientes.

Esses desafios trazem para o direito do trabalho as seguintes questões: se trabalhadores autônomos genuínos são de alguma forma parte do direito do trabalho e, segundo, se todos os trabalhadores individuais deveriam ter acesso a um 'sistema básico de direitos', indo além da igualdade de tratamento e de proteção da saúde e segurança, e, em caso afirmativo, quais tais direitos esse sistema deveria abranger"15 (LEIGHTON; WYNN,2011, p. 4). Identificar as necessidades desses profissionais e buscar organizar uma regulação sistemática que preserve sua autonomia constituem passos básicos na discussão desse tema.

Analisando o contexto da União Européia, Leighton e Brown (2014, p.27) sugerem como potenciais áreas para regulação as seguintes: tributária, de seguridade social, saúde e segurança, discriminação, regulação da profissão, políticas de treinamento e suporte. Um ambiente regulatório favorável afeta de forma positiva a habilidade desses profissionais de encontrar trabalho, de gozar de condições de trabalho dignas, de arcar com o ônus administrativo do trabalho autônomo, de ser capaz de suportar os riscos profissionais e pessoais de sua atividade, de manter sua liberdade profissional e criar sua identificação própria distinta de um empregado e de um empregador (LEIGHTON E BROWN, 2014, p.27).

\footnotetext{
${ }^{13}$ Infelizmente no Brasil os trabalhadores autônomos são considerados como um grupo homogêneo, não existindo dados específicos sobre os ipros.

${ }^{14}$ Para uma análise da promoção do trabalho autônomo no caso de profissionais mais vulneráveis, cf. Blattman; Fiala; Martinez, 2014, 697-752.

15 Tradução livre: "whether the genuine self-employed are a part of employment law at all and, second, whether all individual workers should have access to a 'floor of rights', going beyond the equal treatment and health and safety protections, and, if so, what such rights might encompass".
} 


\section{CONCLUSÃO}

O critério da subordinação jurídica deu ao direito do trabalho um critério sólido para o reconhecimento da relação de emprego que se tornou o foco da proteção trabalhista. Enquanto o trabalho subordinado foi o modelo padrão de relação de trabalho, essa estratégia foi bemsucedida.

Dois elementos parecem ter tornado esse quadro mais complexo do que no passado. Primeiro, trabalhadores quasi subordinados ou em relações de trabalho que de alguma forma de diferenciavam do trabalho típico passaram a se organizar coletivamente e demandar a proteção legal do seu trabalho. As trabalhadoras domésticas constituem o exemplo mais recente desse movimento. Segundo, o trabalho autônomo - genuinamente autônomo e, não, relações de empregos fraudulentas, disfarçadas - passa a ser apresentar em diversas formas no mercado de trabalho. Tanto em razão de avanços tecnológicos, quanto administrativos, que possibilitam a certos profissionais optarem por exercer sua atividade de forma autônoma; quanto em razão de crises econômicas que empurram desempregados para o trabalho autônomo, muitas vezes informal.

Juntos esses dois elementos desestabilizam a subordinação de emprego como o critério definidor da proteção assegurada pelo direito do trabalho. Novos direitos são reconhecidos e novos grupos passam a demandar essa proteção. Por um lado, trabalhadores autônomos vulneráveis, como por exemplo catadores de resíduos nas grandes cidades, constituem um grupo cuja necessidade de proteção do trabalho é latente na nossa sociedade. Por outro, trabalhadores autônomos profissionalmente qualificados, como é o caso dos profissionais liberais, mas não somente esses, exigem maior atenção, estudos e regulações específicas. Nesse contexto, este artigo traz uma reflexão acerca da necessidade da regulação do trabalho autônomo, ou seja, a necessidade de olhar para o outro lado da cerca do trabalho subordinado.

Enquanto alguns países, como a Espanha, já adotaram algum tipo de regulação do trabalho autônomo, o Brasil ainda não avançou nesse sentido. O artigo sugere que identificar as necessidades desses profissionais e buscar organizar uma regulação sistemática que preserve sua autonomia, garante direitos fundamentais e acesso a benefícios sociais constituem passos básicos na discussão desse tema.

\section{RELAÇÃO BIBLIOGRÁFICA}


BARROS, Alice Monteiro de. Trabalhadores Intelectuais. Rev. Trib. Reg. Trab. $3^{\text {a }}$ Reg., Belo Horizonte, v.39, n.69, jan./jun.2004, p.147-165.

BLATTMAN, Christopher; FIALA, Nathan; Martinez, Sebastian. Generating Skilled Self-Employment in Developing Countries: Experimental Evidence from Uganda. The Quarterly Journal of Economics. 2014, pp. 697-752.

FREEDLAND, Mark. From the Contract of Employment to the Personal Work Nexus. Industrial Law Journal, Vol. 35, No. 1, March 2006, pp.1-29.

GOMES, A. V. M., TORTELL, L. A Convenção 189 da OIT sobre Trabalho Decente para Trabalhadoras e Trabalhadores Domésticos: desafios e oportunidades de sua aplicação no Brasil In: Fronteiras da Cidadania.1 ed.São Paulo : Editora Mackenzie, 2015, v.1, p. 34-53.

LEIGHTON, Patricia. The Rise of Europe's Independent Professionals: But Why the Reluctance to Embrace Them? Business Law Review, Volume 35, Issue 3, 2014, pp. 84-92.

LEIGHTON, Patricia; BROWN, Ducan. Future Working: the rise of Europe's independent professionals (ipros). European Forum of Independent Professionals. Disponível on line: http://www.um.es/prinum/uploaded/files/FutureWorkingFullReport-

2\%20final\%20subir\%20web.pdf. Acesso em: 9 de setembro de 2016.

PÉREZ REY, Joaquín. El Régimen Profesional del Trabajo Autónomo Económicamente

Dependiente: Novedades Legales y Jurisprudenciales. Albacete: Editorial Bomarzo, 2016.

RAPELLI, Stéphane. European I-Pros: a study (English language version) 2012. Disponível on line: http://www.pcg.org.uk/sites/default/files//media/documents/RESOURCES/efipreportenglish.pdf. Acesso em: 9 de setembro de 2016.

ROMITA, Arion Sayão. Prestação de Serviços por Trabalhadores Autônomos - Relação de Trabalho ou Relação de Consumo? Revista de Direito do Trabalho, São Paulo| vol. 124, Out - Dez/2006, p. $9-32$. 
SAPPIA, Jorge J et al. Empleo y Flexibilidad Laboral. Leyes 24.465, 24.467 y sus reglamentaciones.

Período de prueba. Trabajo a tiempo parcial. Fomento del empleo. Contrato de aprendizaje. Régimen de la pequeña empresa. Buenos Aires: Astrea, 1996.

SUPIOT, Alain. Crítica del Derecho del Trabajo. Madrid: Ministerio del Trabajo y Asuntos Sociales, 1996. 